\title{
ATMOSPHERIC EFFECTS OF THE COSMIC-RAY MU-MESON COMPONENT
}

\section{V.L. Yanchukovsky}

A.A. Trofimuk Institute of Oil

and Gas Geology and Geophysics SB RAS

Novosibirsk, Russia, YanchukovskiyVL@ipgg.sbras.ru

\author{
V.S. Kuzmenko \\ A.A. Trofimuk Institute of Oil \\ and Gas Geology and Geophysics SB RAS, \\ Novosibirsk, Russia,mp3.87@mail.ru
}

\begin{abstract}
Variations in the intensity of cosmic rays observed in the depth of the atmosphere include the atmospheric component of the variations. Cosmic-ray muon telescopes, along with the barometric effect, have a significant temperature effect due to the instability of detected particles. To take into account atmospheric effects in muon telescope data, meteorological coefficients of muon intensity are found. The meteorological coefficients of the intensity of muons recorded in the
\end{abstract}

depth of the atmosphere are estimated from experimental data, using various methods of factor analysis. The results obtained from experimental data are compared with the results of theoretical calculations. phere.

Keywords: cosmic rays, muons, temperature, atmoset al., 2008; Dmitrieva et al., 2009; Kuzmenko, Yanchukovsky, 2017]. Experimental estimate of the density distribution of temperature coefficients is also difficult because temperature variations of different atmospheric layers are correlated. Therefore, to experimentally estimate the temperature coefficients of muon intensity from results of continuous observations, we have used different methods of data analysis.

\section{METHODS}

To analyze continuous observations, we adopt methods of factor analysis [Enyukov, 1989]: correlation/regression analysis [Draper, Smith, 2007; Ferster, Rents, 1981 ] and method of principal components (PC) [Aivazyan et al., 1989; Aivazyan, 2001].

Muon intensity variations $y$ caused by variations in the temperature of $n$ atmospheric layers are represented as a linear regression equation where the intensity effect is expressed in terms of $x_{1}, x_{2}, x_{3}, \ldots, x_{n}$ :

$$
y=a_{0}+a_{1} x_{1}+a_{2} x_{2}+\ldots+a_{n} x_{n}+\varepsilon
$$

or

$$
Y=A_{0}+\sum_{j=1}^{n} A_{j} X_{j}+\varepsilon .
$$

scopes [Yanchukovsky et al., 2016], it is necessary to correctly account for the contribution of atmospheric effects to data. To do this, we should assess the impact of atmospheric parameters on the muon intensity in the atmosphere. The integral method proposed by Dorman [1957] allows us to account for the temperature effect of the intensity of muons from the entire atmosphere. The method assumes the presence of regular data on the temperature section of the atmosphere and the knowledge of density distribution of temperature coefficients for muons in the atmosphere. Its calculation has been made for Novosibirsk muon telescope-hodoscope and Yakutsk underground complex of muon telescopes [Kuzmenko, Yanchukovsky, 2017]. In practice, however, the results of theoretical calculations should be carefully applied to the correction of observations because all the calculations are usually made with various approximations [Dorman, Yanke, 1971; Berkova
Here, $Y=\left\{y_{1}, \ldots, y_{i}, \ldots, y_{m}\right\}$ is muon intensity variations $\frac{I_{\mathrm{M} i}-\bar{I}_{\mathrm{M}}}{\bar{I}_{\mathrm{M}}} 100=\delta \bar{I}_{\mathrm{M} i}$, the independent variables (factors) $X_{j}=\left\{x_{j 1}, \ldots, x_{j m}\right\}$ are variations in the temperature of the $j$ layer, $T_{j i}-\bar{T}_{j}=\Delta T_{j i}, A_{j}$ is the regression coefficient having the meaning of the temperature coefficient of $j$-layer muon intensity; $\varepsilon$ is the vector of random components, which distinguishes statistical data from data obtained by approximation. The parameters $A_{j}(j=\overline{0, n})$ are determined using the least square method, which for linear regression equations reduces to solving a system of normal equations [Korn, Korn, 1984].

There is another type of multiple regression equa- 
tions, which we will also use - the equation of regression on a standardized scale [Gorlach, 2006]. Represent equation (1) in such a way:

$$
y_{i}=\alpha_{1} x_{1 i}+\alpha_{2} x_{2 i}+\alpha_{3} x_{3 i}+\ldots+\alpha_{n} x_{n i},
$$

where

$$
y_{i}=\frac{y_{i}-\bar{Y}}{\sigma_{Y}} ; \quad x_{j i}=\frac{x_{j i}-\bar{X}_{j}}{\sigma_{X_{j}}} . \quad(i=\overline{1, m})
$$

$(j=\overline{1, n})$ are standardized variables; standardized regression coefficients $\alpha_{j}$ are found by solving the system of equations:

$$
\left\{\begin{array}{l}
r_{Y X_{1}}=\alpha_{1}+\alpha_{2} r_{X_{1} X_{2}}+\alpha_{3} r_{X_{1} X_{3}}+\ldots+\alpha_{n} r_{X_{1} X_{n}} \\
r_{Y X_{2}}=\alpha_{1} r_{X_{2} X_{1}}+\alpha_{2}+\alpha_{3} r_{X_{2} X_{3}}+\ldots+\alpha_{n} r_{X_{2} X_{n}} \\
r_{Y X_{3}}=\alpha_{1} r_{X_{3} X_{1}}+\alpha_{2} r_{X_{3} X_{2}}+\alpha_{3}+\ldots+\alpha_{n} r_{X_{3} X_{n}} \\
\ldots \\
r_{Y X_{n}}=\alpha_{1} r_{X_{n} X_{1}}+\alpha_{2} r_{X_{n} X_{2}}+\alpha_{3} r_{X_{n} X_{3}}+\ldots+\alpha_{n} .
\end{array}\right.
$$

Here $r_{Y X j}, r_{X j X k}$ are coefficients of pair linear correlation between variables. System of equations (3) was solved by the direct Gauss, Cramer, and Gauss-Jordan methods [Ilyin, Poznyak, 2004; Volkov, 1987]. The transition from the resulting standardized coefficients $\alpha_{j}$ to desired multifactor regression coefficients $A_{j}$ is made by the relation

$$
A_{j}=\alpha j \frac{\sigma_{Y}}{\sigma_{X_{j}}} .
$$

The method of principal components [Aivazyan et al., 1989; Aivazyan, 2001], as well as methods of projections to latent structures PLS1 and PLS2 [Esbensen, 2005; Pomerantsev, 2014] have been used by us before [Kuzmenko, Yanchukovsky, 2015] to estimate the density of muon temperature coefficients from experimental data. The iterative algorithm for calculating factors in PC space for PLS1 and PLS2 has been described in detail in [Kuzmenko, Yanchukovsky, 2015]. The comparison of the results obtained by the PC, PLS1, and PLS2 methods shows that PLS2 yields the best result.

The Unscrambler X

[http://www.camo.com/rt/Products/Unscrambler/unscra mbler.html] enables us to adopt the PLS2 method to calculations using four algorithms:

NIPALS is a nonlinear iterative least square algorithm, which helps with the processing in the absence of some values in the data and is suitable for calculating only the first few factors from a dataset [Esbensen, 2005];

ORTHOGONAL SCORES PLS is the classical PLS algorithm involving NIPALS, which does not ensure the processing without some values in data [Martens, Naes, 1991];

WIDE-KERNEL PLS is an algorithm that does not work without some values in data and is best suited for the data with several samples and a large number of variables [Rannar et al., 1994];

KERNEL PLS is an algorithm that is best suited for a large number of samples (thousands of samples with several variables) [Lindgren et al., 1993; de Jong, Ter Braak, 1994; Dayal, McGregor, 1997].

We have employed the first two algorithms before
[Kuzmenko, Yanchukovsky, 2015]. The third algorithm is not to be suited for this problem because it deals with a dataset with a small number of variables and large number of samples (the number of samples means the number of values in datasets for each variable). We therefore apply the fourth PLS KERNEL algorithm to the calculations.

\section{DATA}

The programs [Kuzmenko, Yanchukovsky, 2015] are designed to read and provide the desired format of the following data:

- upper-air sounding data (Bugrinskaya Roshcha, Novosibirsk): temperature, wind speed and direction at different isobaric levels: 1000, 925, 850, 700, 500, 400, 300, 250, 200, 150, 100, $50 \mathrm{mb}$ [https://ruc.noaa.gov/raobs];

- ground-based CR-intensity measurement data: neutron component, the total ionizing component and muon component at different zenith $\left(0^{\circ}, 30^{\circ}, 40^{\circ}, 50^{\circ}\right.$, $60^{\circ}, 67^{\circ}, 71^{\circ}$ ) and azimuth (southeast, northwest, southwest, northeast) angles, as well as atmospheric pressure and surface layer temperature (CR station Novosibirsk [http://cosm-rays.ipgg.sbras.ru]). The analysis is based on daily average observational data for 20042011. This data sampling is determined by the periodicity of upper-air sounding (12 hr).

\section{METEOROLOGICAL COEFFICIENTS OF MUON INTENSITY}

Intensity variations of muons detected at the level $h_{0}$ of the atmosphere at a point with the geomagnetic cutoff threshold $R_{\mathrm{c}}$ can be represented as follows:

$$
\begin{aligned}
& \frac{\Delta J_{\mathrm{M}}}{J_{\mathrm{M}}}\left(h_{0}\right)=\left\{\exp \left[-\int_{h_{0}}^{h} \beta_{\mathrm{M}}(h) d h\right]-1\right\}+\int_{0}^{h} w_{\mathrm{M}}\left(T_{0}, h_{0}, h\right) \Delta T(h) d h+ \\
& +\int_{R_{\mathrm{c}}}^{\infty} \frac{\Delta D}{D}(R) W\left(R, h_{0}\right) d R,
\end{aligned}
$$

where $\beta_{\mathrm{m}}(h)$ is the barometric coefficient of muon intensity; $w_{m}\left(T_{0}, h_{0}, h\right)$ is the function of density of temperature coefficients, which reflects the contribution of atmospheric layers to the creation of the integral temperature effect of intensity; $\Delta T(h)$ are time variations of atmospheric temperature as a function of height; $(\Delta D / D)(R)$ and $W\left(R, h_{0}\right)$ are the spectrum of variations in the primary flux and the coupling coefficients for the CR muon component respectively. Here $R$ is the primary particle rigidity, $h$ is the atmospheric pressure, $h_{0}$ and $T_{0}$ are pressure and temperature of the atmosphere at the level of muon observation.

Muon intensity variations (5) can be represented as a linear regression equation in which the barometric and temperature effects, as well as the effect of the primary $\mathrm{CR}$ variation, are expressed in terms of the factors $x_{1}, x_{2}$, $x_{3}, x_{4}$ :

$$
y=a_{0}+a_{1} x_{1}+a_{2} x_{2}+a_{3} x_{3}+a_{4} x_{4}+\varepsilon .
$$

The resulting factor $y$ refers to muon intensity varia- 
tions $\frac{J_{\mathrm{M} i}-\bar{J}_{\mathrm{M}}}{\bar{J}_{\mathrm{M}}} 100=\delta J_{\mathrm{M} i} ; x_{1}$, to atmospheric pressure variations $h_{i}-h_{0}=\Delta h_{i} ; x_{2}$, to variations in the temperature of a layer with variable mass

$\left(T_{n i}-\bar{T}_{n}\right)\left(P_{i}-950\right)=\Delta t_{i}\left(P_{i}-950\right) ; x_{3}$ refers to variations in mass average atmospheric temperature $T_{\mathrm{cм} i}-\bar{T}_{\mathrm{cm}}=\Delta T_{\text {см } i}, ; x_{4}$, to variations of neutron component intensity $\frac{N_{i}-\bar{N}}{\bar{N}} 100=\delta n_{i}$ caused by changes in the spectrum of primary CR flux.

Equation (6) can be represented in a standardized scale similarly to Equation (2).

Find standardized regression coefficients by solving system of equations (3). Then proceed to the desired multifactor regression coefficients, using ratio (4). The coefficients thus obtained are shown in Table 1.

The results allow us to identify directly the temperature component of muon intensity variations in initial observations without employing, as was done previously in [Kuzmenko, Yanchukovsky, 2015], the spectrographic analysis of observed variations [Dvornikov et al., 1972; Yanchukovsky et al., 2011].

\section{DENSITY OF TEMPERATURE COEFFICIENTS OF MUON INTENSITY}

Correlation/regression analysis. The atmosphere is arbitrarily divided into 11 layers according to upper-air data, which are presented for 11 isobars: 925, 850, 700, 500, 400, 300, 250, 200, 150, 100, and and $50 \mathrm{mb}$. Therefore, in expression (2) $n=11$. Solving system of equations (3), find the standardized regression coeffi- cients. Using (4), convert them into the multifactor regression coefficients having the meaning of temperature coefficients. In passing to the density of temperature coefficients of muon intensity, as before, we account for the weighting factor depending on the relative weight of the atmospheric layer $\Delta h_{i} / \sum_{i=1}^{n} \Delta h_{i}$, where $\Delta h_{i}=\{75,50$, $50,50,50,75,100,150,175,125,50\} \mathrm{mb}$.

The results obtained from the correlation/regression analysis for muons recorded at zenith angles from $0^{\circ}$ to $60^{\circ}$ are summarized in Table 2.

The PLS2 method with the use of the PLS KERNEL algorithm. Temperature coefficients of muon intensity in the atmosphere for different zenith angles found by the PLS2 method (PLS KERNEL algorithm) are listed in Table 3.

In passing to the density of temperature coefficients of muon intensity, as previously we consider the relative mass $\Delta h$ of the atmospheric layer.

The densities of muon intensity temperature coefficients obtained by PLS2 are shown in Table 4.

The choice of the number of principal components from 1 to 3 slightly affects the result. When including more than three principal components, we lose information in the initial data and have non-physical dynamics of resulting curves.

\section{RESULTS AND DISCUSSION}

For comparison, the results are shown in Figures 1 and 2. Figure 1 displays density distributions of temperature coefficients of vertically recorded (at a zenith angle of $0^{\circ}$ ) muon intensity without a shield (Figure $1, a$ ) and with a 0.56 GeV shield (Figure 1,b).

Coefficients of multifactor regression

\begin{tabular}{|c|c|c|c|c|c|c|c|c|}
\hline \multirow{2}{*}{$A_{\mathrm{j}}$} & \multicolumn{9}{|c|}{ Zenith angle $\theta$, deg. } \\
\cline { 2 - 9 } & O.I. & \multicolumn{1}{|c|}{0} & 30 & 40 & 50 & 60 & 67 & 71 \\
\hline$A_{1}, \% / \mathrm{mb}$ & -0.185 & -0.158 & -0.158 & -0.158 & -0.173 & -0.186 & -0.245 & -0.3 \\
& \pm 0.025 & \pm 0.027 & \pm 0.029 & \pm 0.032 & \pm 0.034 & \pm 0.056 & \pm 0.061 & \pm 0.064 \\
\hline$A_{2}, \% /{ }^{\circ} \mathrm{C}$, & -0.0283 & -0.065 & -0.0652 & -0.0643 & -0.066 & -0.065 & -0.068 & -0.07 \\
$10-2$ & \pm 0.0056 & \pm 0.0046 & \pm 0.0042 & \pm 0.038 & \pm 0.0048 & \pm 0.0058 & \pm 0.0072 & \pm 0.009 \\
\hline$A_{3}, \% /{ }^{\circ} \mathrm{C}$ & -0.227 & -0.228 & -0.228 & -0.242 & -0.256 & -0.262 & -0.308 & -0.31 \\
& \pm 0.023 & \pm 0.025 & \pm 0.024 & \pm 0.028 & \pm 0.031 & \pm 0.035 & \pm 0.042 & \pm 0.052 \\
\hline$A_{4}$ & 0.381 & 0.383 & 0.356 & 0.329 & 0.288 & 0.260 & 0.260 & 0.260 \\
& \pm 0.0302 & \pm 0.0306 & \pm 0.0275 & \pm 0.0268 & \pm 0.0246 & \pm 0.034 & \pm 0.046 & \pm 0.052 \\
\hline
\end{tabular}

Here, $A_{1}$ is the barometric coefficient, $A_{2}$ is the temperature coefficient of the layer of variable mass (surface layer), $A_{3}$ is the temperature coefficient of the mass average temperature of the atmosphere, and $A_{4}$ is the regression coefficient with neutron monitor data on the intensity of muons recorded without a lead shield (O.I.) and with a lead shield at zenith angles of $0,30,40,50,60,67$, and $71^{\circ}$. 
Table 2

Density of temperature coefficients of muon intensity in the atmosphere $w(h)$, obtained from the correlation/regression analysis

\begin{tabular}{|c|c|c|c|c|c|c|}
\hline \multirow{2}{*}{$\begin{array}{l}\text { Depth of the } \\
\text { atmosphere } \\
h, \mathrm{mb}\end{array}$} & \multicolumn{6}{|c|}{ Zenith angle $\theta$, deg. } \\
\hline & O.I. & 0 & 30 & 40 & 50 & 60 \\
\hline 50 & $\begin{array}{l}-0.152 \\
\pm 0.0605\end{array}$ & $\begin{array}{l}-0.245 \\
\pm 0.0975\end{array}$ & $\begin{array}{l}-0.250 \\
\pm 0.0985\end{array}$ & $\begin{array}{l}-0.190 \\
\pm 0.0703\end{array}$ & $\begin{array}{l}-0.190 \\
\pm 0.0804\end{array}$ & $\begin{array}{l}-0.348 \\
\pm 0.0909\end{array}$ \\
\hline 100 & $\begin{array}{l}-0.385 \\
\pm 0.0723\end{array}$ & $\begin{array}{l}-0.501 \\
\pm 0.0939\end{array}$ & $\begin{array}{l}-0.538 \\
\pm 0.0935\end{array}$ & $\begin{array}{l}-0.348 \\
\pm 0.0731\end{array}$ & $\begin{array}{l}-0.649 \\
\pm 0.0957\end{array}$ & $\begin{array}{l}-0.484 \\
\pm 0.0913\end{array}$ \\
\hline 150 & $\begin{array}{l}-0.344 \\
\pm 0.0417\end{array}$ & $\begin{array}{l}-0.659 \\
\pm 0.0798\end{array}$ & $\begin{array}{l}-0.626 \\
\pm 0.1217\end{array}$ & $\begin{array}{l}-0.626 \\
\pm 0.0703\end{array}$ & $\begin{array}{l}-0.728 \\
\pm 0.0806\end{array}$ & $\begin{array}{l}-0.637 \\
\pm 0.0879\end{array}$ \\
\hline 200 & $\begin{array}{l}-0.399 \\
\pm 0.0589\end{array}$ & $\begin{array}{l}-0.537 \\
\pm 0.0794\end{array}$ & $\begin{array}{l}-0.538 \\
\pm 0.1184\end{array}$ & $\begin{array}{l}-0.503 \\
\pm 0.0982\end{array}$ & $\begin{array}{l}-0.856 \\
\pm 0.0987\end{array}$ & $\begin{array}{l}-0.565 \\
\pm 0.0949\end{array}$ \\
\hline 250 & $\begin{array}{l}-0.184 \\
\pm 0.0738\end{array}$ & $\begin{array}{l}-0.193 \\
\pm 0.0798\end{array}$ & $\begin{array}{l}-0.153 \\
\pm 0.0696\end{array}$ & $\begin{array}{l}-0.330 \\
\pm 0.0830\end{array}$ & $\begin{array}{l}-0.237 \\
\pm 0.0906\end{array}$ & $\begin{array}{l}-0.252 \\
\pm 0.0266\end{array}$ \\
\hline 300 & $\begin{array}{l}-0.164 \\
\pm 0.0712\end{array}$ & $\begin{array}{l}-0.194 \\
\pm 0.0844\end{array}$ & $\begin{array}{l}-0.238 \\
\pm 0.0853\end{array}$ & $\begin{array}{l}-0.235 \\
\pm 0.0906\end{array}$ & $\begin{array}{l}-0.272 \\
\pm 0.0948\end{array}$ & $\begin{array}{l}-0.325 \\
\pm 0.1056\end{array}$ \\
\hline 400 & $\begin{array}{l}-0.235 \\
\pm 0.0820\end{array}$ & $\begin{array}{l}-0.235 \\
\pm 0.0820\end{array}$ & $\begin{array}{l}-0.258 \\
\pm 0.0920\end{array}$ & $\begin{array}{l}-0.310 \\
\pm 0.0932\end{array}$ & $\begin{array}{l}-0.284 \\
\pm 0.0953\end{array}$ & $\begin{array}{l}-0.310 \\
\pm 0.1092\end{array}$ \\
\hline 500 & $\begin{array}{l}-0.195 \\
\pm 0.0681\end{array}$ & $\begin{array}{l}-0.283 \\
\pm 0.0988\end{array}$ & $\begin{array}{l}-0.298 \\
\pm 0.117\end{array}$ & $\begin{array}{l}-0.318 \\
\pm 0.127\end{array}$ & $\begin{array}{l}-0.325 \\
\pm 0.0975\end{array}$ & $\begin{array}{l}-0.395 \\
\pm 0.136\end{array}$ \\
\hline 700 & $\begin{array}{l}-0.275 \\
\pm 0.0825\end{array}$ & $\begin{array}{l}-0.371 \\
\pm 0.111\end{array}$ & $\begin{array}{l}-0.325 \\
\pm 0.0990\end{array}$ & $\begin{array}{l}-0.355 \\
\pm 0.136\end{array}$ & $\begin{array}{l}-0.385 \\
\pm 0.0979\end{array}$ & $\begin{array}{l}-0.260 \\
\pm 0.1054\end{array}$ \\
\hline 850 & $\begin{array}{l}-0.225 \\
\pm 0.0602\end{array}$ & $\begin{array}{l}-0.315 \\
\pm 0.0948\end{array}$ & $\begin{array}{l}-0.363 \\
\pm 0.113\end{array}$ & $\begin{array}{l}-0.283 \\
\pm 0.0909\end{array}$ & $\begin{array}{l}-0.450 \\
\pm 0.0938\end{array}$ & $\begin{array}{l}-0.340 \\
\pm 0.1077\end{array}$ \\
\hline 925 & $\begin{array}{l}-0.279 \\
\pm 0.0599\end{array}$ & $\begin{array}{l}-0.381 \\
\pm 0.0818\end{array}$ & $\begin{array}{l}-0.506 \\
\pm 0.150\end{array}$ & $\begin{array}{l}-0.351 \\
\pm 0.123\end{array}$ & $\begin{array}{l}-0.630 \\
\pm 0.145\end{array}$ & $\begin{array}{l}-0.500 \\
\pm 0.147\end{array}$ \\
\hline
\end{tabular}

Table 3

Temperature coefficients of muon intensity determined using the PLS2 method (KERNEL algorithm)

\begin{tabular}{|r|l|l|l|l|l|l|l|l|}
\hline $\begin{array}{c}\text { Depth of } \\
\text { the atmos- } \\
\text { phere } \\
h, \mathrm{mb}\end{array}$ & 0 & 30 & 40 & 50 & 60 & 67 & 71 & O.I. \\
\cline { 2 - 9 } & & & & & & & & \\
\hline \multirow{2}{*}{50} & -0.0470 & -0.0471 & -0.0475 & -0.0567 & -0.0503 & -0.0570 & -0.0388 & -0.0384 \\
& \pm 0.0034 & \pm 0.0072 & \pm 0.0036 & \pm 0.0061 & \pm 0.0053 & \pm 0.0072 & \pm 0.0161 & \pm 0.0034 \\
\hline \multirow{2}{*}{100} & -0.0392 & -0.0392 & -0.0395 & -0.0472 & -0.0419 & -0.0475 & -0.0323 & -0.0320 \\
& \pm 0.0023 & \pm 0.0054 & \pm 0.0043 & \pm 0.0048 & \pm 0.0044 & \pm 0.0046 & \pm 0.0125 & \pm 0.0023 \\
\hline \multirow{2}{*}{150} & -0.0324 & -0.0324 & -0.0327 & -0.0391 & -0.0346 & -0.0392 & -0.0267 & $-0,0264$ \\
& \pm 0.0017 & \pm 0.0042 & \pm 0.0037 & \pm 0.0030 & \pm 0.0031 & \pm 0.0041 & \pm 0.0110 & \pm 0.0017 \\
\hline \multirow{2}{*}{200} & -0.0299 & -0.0300 & -0.0302 & -0.0361 & -0.0320 & -0.0363 & -0.0247 & -0.0244 \\
& \pm 0.0020 & \pm 0.0044 & \pm 0.0037 & \pm 0.0039 & \pm 0.0031 & \pm 0.0036 & \pm 0.0098 & \pm 0.0020 \\
\hline \multirow{2}{*}{250} & -0.0276 & -0.0276 & -0.0278 & -0.0333 & -0.0295 & -0.0334 & -0.0227 & -0.0225 \\
& \pm 0.0018 & \pm 0.0042 & \pm 0.0035 & \pm 0.0035 & \pm 0.0031 & \pm 0.0041 & \pm 0.0090 & \pm 0.0018 \\
\hline \multirow{2}{*}{300} & -0.0214 & -0.0214 & -0.0216 & -0.0258 & -0.0228 & -0.0259 & -0.0176 & $-0,0174$ \\
& \pm 0.0023 & \pm 0.0041 & \pm 0.0042 & \pm 0.0030 & \pm 0.0036 & \pm 0.0046 & \pm 0.0074 & \pm 0.0023 \\
\hline \multirow{2}{*}{400} & -0.0160 & -0.0160 & -0.0162 & -0.0193 & -0.0171 & -0.0194 & -0.0132 & -0.0131 \\
& \pm 0.0028 & \pm 0.0045 & \pm 0.0042 & \pm 0.0030 & \pm 0.0040 & \pm 0.0051 & \pm 0.0067 & \pm 0.0029 \\
\hline \multirow{2}{*}{500} & -0.0144 & -0.0144 & -0.0145 & -0.0174 & -0.0154 & -0.0175 & -0.0119 & -0.0118 \\
& \pm 0.0034 & \pm 0.0057 & \pm 0.0058 & \pm 0.0052 & \pm 0.0053 & \pm 0.0072 & \pm 0.0067 & \pm 0.0034 \\
\hline \multirow{2}{*}{700} & -0.0160 & -0.0160 & -0.0161 & -0.0193 & -0.0171 & -0.0194 & -0.0132 & -0.0130 \\
& \pm 0.0032 & \pm 0.0049 & \pm 0.0048 & \pm 0.0039 & \pm 0.0036 & \pm 0.0056 & \pm 0.0067 & \pm 0.0032 \\
\hline \multirow{2}{*}{850} & -0.0155 & -0.0156 & -0.0157 & -0.0187 & -0.0166 & -0.01883 & -0.0128 & -0.0127 \\
\pm 0.0032 & \pm 0.0049 & \pm 0.0050 & \pm 0.0039 & \pm 0.0044 & \pm 0.00513 & \pm 0.0067 & \pm 0.0032 \\
\hline
\end{tabular}


Table 4

Density of temperature coefficients obtained by the PLS2 method (KERNEL algorithm)

\begin{tabular}{|c|c|c|c|c|c|c|c|c|}
\hline \multirow{2}{*}{$\begin{array}{c}\text { Depth of } \\
\text { the atmos- } \\
\text { phere } \\
h, \mathrm{mb}\end{array}$} & 0 & 30 & 40 & 50 & 60 & 67 & 71 & O.I. \\
\cline { 2 - 9 } & & & & & & & & \\
\hline \multirow{2}{*}{50} & -0.580 & -0.581 & -0.585 & -0.700 & -0.620 & -0.703 & -0.479 & -0.474 \\
& \pm 0.041 & \pm 0.089 & \pm 0.044 & \pm 0.075 & \pm 0.066 & \pm 0.088 & \pm 0.198 & \pm 0.041 \\
\hline \multirow{2}{*}{100} & -0.725 & -0.726 & -0.731 & -0.874 & -0.775 & -0.879 & -0.598 & -0.592 \\
& \pm 0.043 & \pm 0.099 & \pm 0.080 & \pm 0.088 & \pm 0.082 & \pm 0.085 & \pm 0.232 & \pm 0.043 \\
\hline \multirow{2}{*}{150} & -0.599 & -0.600 & -0.604 & -0.723 & -0.640 & -0.726 & -0.494 & -0.489 \\
& \pm 0.031 & \pm 0.077 & \pm 0.068 & \pm 0.056 & \pm 0.057 & \pm 0.076 & \pm 0.203 & \pm 0.031 \\
\hline \multirow{2}{*}{200} & -0.554 & -0.555 & -0.559 & -0.668 & -0.592 & -0.671 & -0.457 & -0.452 \\
& \pm 0.037 & \pm 0.081 & \pm 0.068 & \pm 0.072 & \pm 0.057 & \pm 0.066 & \pm 0.181 & \pm 0.037 \\
\hline \multirow{2}{*}{250} & -0.510 & -0.511 & -0.515 & -0.616 & -0.546 & -0.619 & -0.421 & -0.417 \\
& \pm 0.034 & \pm 0.078 & \pm 0.065 & \pm 0.064 & \pm 0.057 & \pm 0.076 & \pm 0.167 & \pm 0.034 \\
\hline \multirow{2}{*}{300} & -0.263 & -0.264 & -0.266 & -0.318 & -0.282 & -0.319 & -0.217 & -0.215 \\
& \pm 0.029 & \pm 0.050 & \pm 0.051 & \pm 0.037 & \pm 0.044 & \pm 0.057 & \pm 0.092 & \pm 0.029 \\
\hline \multirow{2}{*}{400} & -0.148 & -0.148 & -0.150 & -0.179 & -0.159 & -0.180 & -0.122 & -0.121 \\
& \pm 0.026 & \pm 0.041 & \pm 0.039 & \pm 0.028 & \pm 0.037 & \pm 0.047 & \pm 0.062 & \pm 0.026 \\
\hline \multirow{2}{*}{500} & -0.089 & -0.089 & -0.090 & -0.107 & -0.095 & -0.108 & -0.073 & -0.073 \\
& \pm 0.021 & \pm 0.035 & \pm 0.036 & \pm 0.032 & \pm 0.033 & \pm 0.047 & \pm 0.041 & \pm 0.021 \\
\hline \multirow{2}{*}{700} & -0.084 & -0.085 & -0.085 & -0.102 & -0.090 & -0.102 & -0.070 & -0.069 \\
& \pm 0.017 & \pm 0.026 & \pm 0.025 & \pm 0.021 & \pm 0.019 & \pm 0.030 & \pm 0.035 & \pm 0.017 \\
\hline \multirow{2}{*}{850} & -0.115 & -0.115 & -0.116 & -0.139 & -0.123 & -0.139 & -0.095 & -0.094 \\
& \pm 0.024 & \pm 0.036 & \pm 0.037 & \pm 0.029 & \pm 0.033 & \pm 0.038 & \pm 0.049 & \pm 0.024 \\
\hline \multirow{2}{*}{925} & -0.313 & -0.314 & -0.316 & -0.378 & -0.335 & -0.380 & -0.258 & -0.256 \\
& \pm 0.067 & \pm 0.093 & \pm 0.111 & \pm 0.087 & \pm 0.099 & \pm 0.133 & \pm 0.138 & \pm 0.067 \\
\hline
\end{tabular}
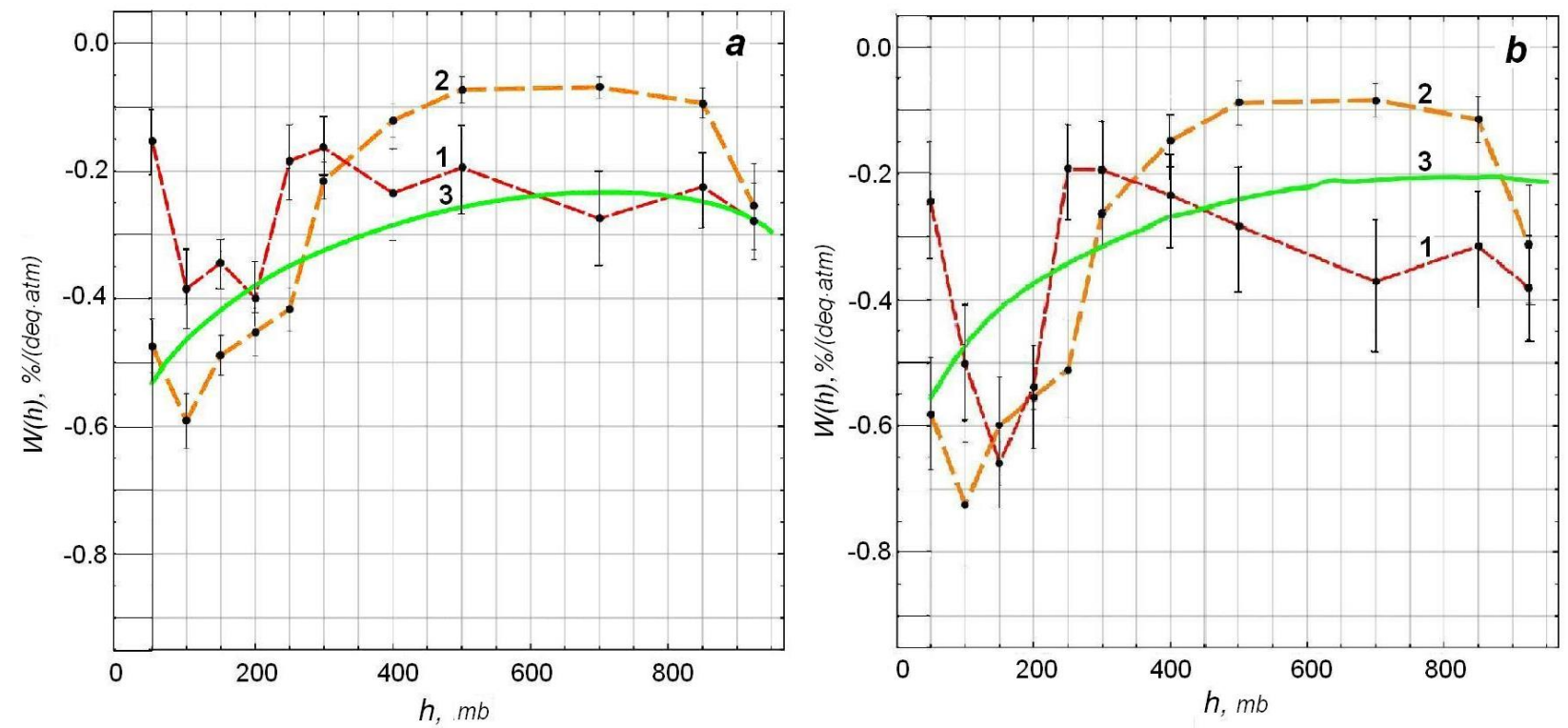

Figure 1. Density distribution of temperature coefficients of the intensity for muons recorded at sea level at a zenith angle of $0^{\circ}$ without a shield $(a)$ and with a shield $(\Delta \varepsilon=0.56 \mathrm{GeV})(b)$ 

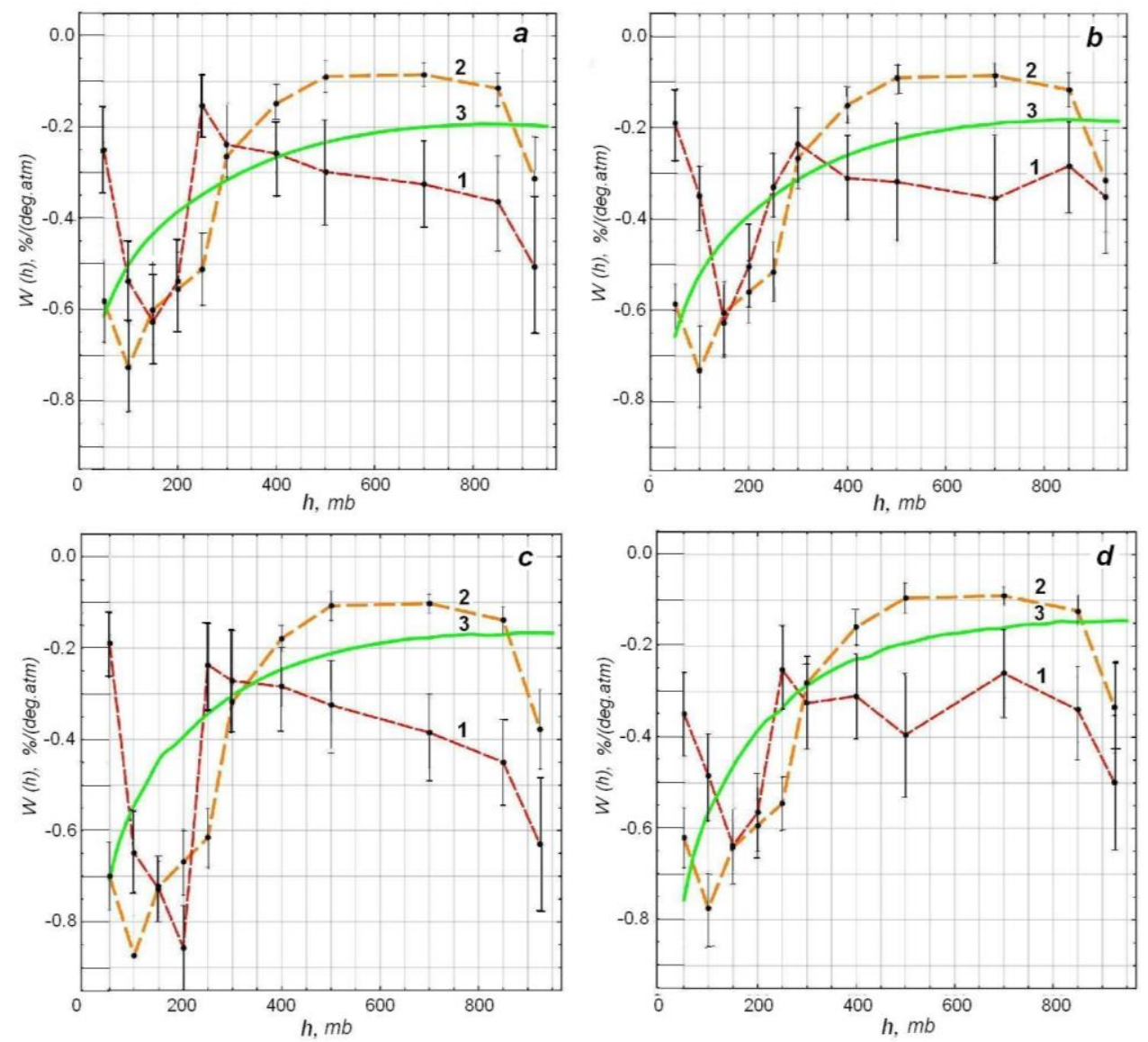

Figure 2. Density distribution of temperature coefficients of the intensity for muons recorded at sea level at zenith angles of $30^{\circ}(a), 40^{\circ}(b), 50^{\circ}(c)$, and $60^{\circ}(d)$

Figure 2 shows density distributions of temperature coefficients for muons recorded at different zenith angles: $30^{\circ}(a), 40^{\circ}(b), 50^{\circ}(c)$, and $60^{\circ}(d)$.

These distributions have been obtained by different methods: from experimental data using the correlation/regression analysis (curve 1), by the PC PLS2 method (curve 2), from theoretical calculations (curve 3 ). To depths of $<400 \mathrm{mb}$, the results of the two methods within the limits of error coincide, and begin to differ at depths of $>400 \mathrm{mb}$. This can be explained by the fact that the PLS2 method in selecting the optimal number of principal components accounts for the statistical significance of variables in the total effect. This method (KERNEL algorithm) allows us to find the temperature coefficients of muon intensity from experimental data with greater accuracy than the correlation/regression analysis. The theoretically calculated distributions have better agreement with those found by PLS2 (KERNEL algorithm) for the following values of initial parameters: $L_{\mathrm{p}}=70 \mathrm{~g} / \mathrm{cm}^{2}, l_{\pi}=110 \mathrm{~g} / \mathrm{cm}^{2}, \gamma=2.75$. Where $L_{\mathrm{p}}$ is the absorption range of protons, $l_{\pi}$ is the absorption range of pions, $\gamma$ is the component of the power spectrum of the primary cosmic-ray flux.

\section{CONCLUSION}

It is usually difficult to experimentally estimate density distributions of temperature coefficients because temperature variations in different atmospheric layers are correlated. We have shown that for the experimental estimate of the temperature coefficients of muon intensity from results of continuous observations, the method of principal components PLS2 (KERNEL algorithm) is more efficient and accurate than the multifactor regression analysis methods.

We used experimental data from the Unique Research Facility Russian National Network of CosmicRay Stations.

\section{REFERENCES}

Aivazyan S.A. Prikladnaya Statistika $i$ Osnovy Ekonometriki [Applied Statistics and Foundations of Econometrics]. Moscow, Yuniti Publ., 2001, 503 p. (In Russian).

Aivazyan S.A., Bukhshtaber V.M., Enyukov I.S., Meshalkin L.D. Prikladnaya Statistika. Klassifikatsiya i Snizhenie Razmernosti [Applied Statistics. Classification and Dimension Lowering]. Moscow, Finansy i Statistika Publ., 1989. 607 p. (In Russian).

Berkova M.D., Belov A.V., Eroshenko E.A., Yanke V.G. Temperature effect of the muon component of cosmic ray and practical possibilities of its accounting. Proc. 21st ECRS. Kosice, Slovakia, 9-12 September 2008, 2008, pp. 123-126.

Dayal B.S., McGregor J.F. Improved PLS Algorithms. J. Chemometrics, 1997, vol. 11, pp. 73-65.

de Jong S., Ter Braak C. Comments on the PLS kernel algorithm. J. Chemometrics, 1994, vol. 8, pp. 169-174.

Dmitrieva A.N., Kokoulin R.P., Petruhin A.A., Timashov D.A. Temperature coefficients for muons under different zenith angles. Izvestiya RAN. Ser. Fizicheskaya 
[Bull. of the Russian Academy of Sciences: Physics]. 2009, vol. 73, no. 3, pp. 371-374. (In Russian).

Dorman L.I. Variatsii kosmicheskikh luchei [Cosmic Ray Variations]. Moscow, Gostekhizdat Publ., 1957. 285 p. (In Russian).

Dorman L.I. Meteorologicheskie effekty kosmicheskikh luchei [Meteorological Effects of Cosmic Rays]. Moscow, Nauka Publ., 1972. 211 p. (In Russian).

Dorman L.I. Experimentalnye i teoreticheskie osnovy astrofiziki kosmicheskikh luchei [Experimental and Theoretical Foundations of Astrophysics of Cosmic Rays]. Moscow, Nauka Publ., 1975. 462 p. (In Russian).

Dorman L.I., Yanke V.G. On theory of meteorological effects of cosmic rays. Izvestiya AN SSSR. Ser. Fizicheskaya [Bull. of the Russian Academy of Sciences: Physics]. 1971, vol. 35, no. 12, pp. 2556-2570. (In Russian).

Draper N.R., Smith H. Applied Regression Analysis. 3rd Edition by John Wiley \& Sons Inc. 1998, 736 p.

Dvornikov V.M., Dorman L.I., Luzov A.A., Sergeev A.V., Yanchukovsky A.L. Analysis of cosmic ray variations of magnetospheric and interplanetary origin from the spectrograph data. Izvestiya AN SSSR. Ser. Fizicheskaya [Bull. of the Russian Academy of Sciences: Physics]. 1972, vol. 36, no. 11, pp. 2427-2434. (In Russian).

Dvornikov V.M., Sdobnov V.E., Kravtsova M.V. Cosmic ray modulation by regular electromagnetic fields in the heliosphere during solar proton events. Izvestiya RAN. Ser. Fizicheskaya [Bull. of the Russian Academy of Sciences. Physics]. 2005, vol. 69, no. 6, pp. 821-824.

Enyukov I.S. Faktornyi, diskriminantnyi i klasternyi analiz [Factorial, Discriminant, and Cluster Analysis]. Moscow, Finansy i Statistika Publ., 1989. 215 p. (In Russian).

Esbensen K. Analiz mnogomernykh dannykh. Izbrannye glavy [Analysis of Multidimensional Data. Selected Chapters / Trans. From English. S.V. Kucheryavsky/Ed. O.E. Rodionova] Chernogolovka, IPCP RAN Publ., 2005. 160 p. (In Russian).

Ferster E., Rents B. Metody korrelyatsionnogo i regressionnogo analiza [Methods of Correlation and Regression Analysis]. Moscow, Finansy i Statistika Publ., 1981. 302 p. (In Russian).

Gorlach B.A. Matematika [Mathematics]. Moscow, Nauka Publ., 2006. 911 p. (In Russian).

Ilyin V.A, Poznyak E.G. Lineynaya algebra: Uchebnik dlya vuzov [Linear Algebra: A Textbook for High Schools. 6th ed.]. Moscow, Fizmatlit Publ., 2004. 280 p. (In Russian).

Kichigin G.N., Kravtsova M.V., Sdobnov V.E. Parameters of current systems in the magnetosphere as derived from observations of cosmic rays during the June 2015 magnetic storm. Solar-Terr. Phys. 2017, vol. 3, no. 3, pp. 13-17. DOI $10.12737 /$ stp-33201702.
Korn G., Korn T. Spravochnik po matematike dlya nauchnykh rabotnikov $i$ inzhenerov [A Handbook on Mathematics for Scientists and Engineers]. Moscow, Nauka Publ., 1984. 831 p. (In Russian).

Kuzmenko V.S., Yanchukovsky V.L. Determination of density of temperature coefficients the Earth's atmosphere muons. Solar-Terr. Phys. 2015, vol. 1, iss. 2, pp. 91-96. (In Russian). DOI: 10.12737/10403.

Kuzmenko V.S., Yanchukovsky V.L. Distribution of temperature coefficient density for muons in the atmosphere. Solar-Terr. Phys. 2017, vol. 3, iss. 4, pp. 93-102.

Lindgren F., Geladi P., Wold S. The kernel algorithm for PLS. J. Chemometrics. 1993, vol. 7, pp. 45-59.

Martens H., Naes T. Multivariate Calibration. Chichester, UK: John Wiley and Sons, 1991.

Pomerantsev A.L. Khemometrika $v$ Excel: Uchebnoe posobie [Chemometrics in Excel: Tutorial]. Tomsk, TPU Publ., 2014. 435 p. (In Russian).

Rannar S., Lindgren F., Geladi P., Wold S. A PLS kernel algorithm for data sets with many variables and fewer objects. Pt. 1: Theory and Algorithm. J. Chemometrics. 1994, vol. 8, pp. 111-125.

Volkov E.A. Chislennye metody [Numerical Methods]. Moscow, Fizmatlit Publ., 2003. 367 p. (In Russian).

Yanchukovsky V.L., Kuzmenko V.S., Antsyz E.N. Results of cosmic ray monitoring with a multichannel complex. Geomagnetism and Aeronomy. 2011, vol. 51, no. 7, pp. 893-896.

Yanchukovsky V.L., Grigoryev V.G., Krymsky G.F., Kuz'menko V.S., Molchanov A.D. Receiving vectors of muon telescope of cosmic ray station Novosibirsk. Solar-Terr. Phys. 2016, vol. 2, iss. 1, pp. 103-119. DOI: 10.12737/19883.

URL: http://cosm-rays.ipgg.sbras.ru (accessed November 23, 2017). 2017).

URL: https://ruc.noaa.gov/raobs (accessed February 17,

URL: http://www.camo.com/rt/Products/Unscrambler/uns crambler.html (accessed February 17, 2017).

How to cite this article

Yanchukovsky V.L., Kuzmenko V.S. Atmospheric effects of the cosmic-ray mu-meson component. Solar-Terrestrial Physics. 2018. vol. 4, iss. 3, pp. 76-82. DOI: $10.12737 / \mathrm{stp}-43201810$. 